\title{
Las ondas constitucionales. Apuntes preliminares para una propuesta comprensiva sociocultural de la tensión y expansión de lo jurídico-político latinoamericano
}

\author{
Henry Forero-Medina \\ Universidad de Buenos Aires \\ forero_henry@yahoo.com.mx \\ José Daniel Fonseca Sandoval \\ Universidad de Santo Tomás, Colombia \\ jfonsandoval@hotmail.com \\ Diego Mauricio Sánchez \\ Universidad de Santo Tomás, Colombia \\ sanchezdima@hotmail.com \\ Yurley Patricia Benitez \\ Universidad de Santo Tomás, Colombia \\ yurpat11@hotmail.com \\ Jhonatan Rodríguez \\ Universidad de Santo Tomás, Colombia \\ jhonatanharrys@hotmail.com
}

\begin{abstract}
Resumen: El presente texto es una aproximación metodológica y conceptual sociocultural desde una mirada crítica, decolonial, exploratoria e imaginativa, con la cual se pretende establecer algunos presupuestos y ejes de análisis que permitan comprender el fenómeno social de la centralidad discursiva de lo jurídico-político hegemónico. A su vez, pretende propiciar debates y reflexiones sobre la condición social, el lazo social y el sentido social mediante otros enfoques y perspectivas de índole interdisciplinaria, como elemento característico de un modo de pensar y hacer ciencias sociales situadas y emergentes. Es así que en un primer momento se revisarán los aportes y atributos del análisis crítico del discurso; en el segundo y tercer momentos se describirá y sustentará el trazo y la fundamentación de la metáfora de las ondas junto con el de la semiosfera estatal, como estrategias figurativas de las relaciones de dominación jurídicopolíticamente mediadas y espacializa-
\end{abstract}


das; y en el último se abordará la relevancia de la contraposición entre los conceptos de pueblo y multitud y su incidencia en la potencialidad de lo emancipatorio y la resignificación del espacio discursivo constituyente. Al final, plantearemos algunas consideraciones a manera de conclusión.

Palabras clave: Discurso, semiosfera, metáfora, constitución, ondas, jurídicopolítico, multitud.

Abstract: The present text is a methodological and sociocultural conceptual approach from a critical, decolonial, exploratory and imaginative perspective, with which it is intended to establish some assumptions and axes of analysis that allow understanding the social phenomenon of the discursive centrality of the hegemonic juridical-political, as well as encouraging debates and reflections on the social condition, the social bond and the social sense through other interdisciplinary approaches and perspectives, as a characteristic element of a way of thinking and doing situated and emerging social sciences. Thus, at a first moment the contributions and attributes of the critical analysis of discourse will be reviewed; in the second and third moments, the outline and the foundation of the wave metaphor will be described and sustained together with that of the state semiosphere, as figurative strategies of the politically mediated and spatialized relations of legal domination, in the last the relevance will be addressed of the contrast between the concepts of people and the multitude and their impact on the potentiality of the emancipatory and the resignification of the discursive constituent space, and at the end some considerations.

Key words: Speech, semiosphere, metaphor, constitution, waves, juridical, multitude. 


\section{INTRODUCCIÓN}

Los estudios sociales críticos latinoamericanos pretenden examinar los usos y efectos epistémicos y culturales de los paradigmas hegemónicos tradicionales implantados sobre lo instituyente y constitutivo del orden social. Dichos estudios se centran en realizar una distorsión y resignificación de los modos en que se ha narrado lo real social, lo cual ha posibilitado pensar maneras divergentes y otras de explicar y comprender los registros y variaciones sobre lo político y jurídico y su incidencia en los procesos de subjetivación y las relaciones de poder y saber en América Latina. En este contexto, un hecho social relevante a observar y estudiar es la configuración de una Constitución como discurso que contenga elementos y características susceptibles de descripción y comprensión sociocultural.

Que la Constitución se entienda como un discurso (Broekman, 1997), implica que en ella deberían consignarse sentidos y significados más allá de su carácter estrictamente jurídico — como norma jerárquica del sistema jurídico. Lo anterior implica asumir que existen múltiples lecturas y relatos de la narrativa constitucional que contradicen o distorsionan el discurso oficial o dominante (netamente jurídico). Tal percepción de las diferentes perspectivas de comprensión del discurso constitucional despliega asimismo prácticas de significación y sentido que demuestran que la Constitución no es una institución quieta sino un intercambio de relatos, posiciones y espacios que admite distintas y diversas apropiaciones y distorsiones narrativas, emitidas por los grupos sociales plurales que integran la realidad ficcional regentada por el Estado:

Para Schmitt la Constitución significa por una parte la «condición completa de unidad y orden político» y por otra la «unidad política del pueblo (concepto que se cuestionará y modificará en acápites posteriores)». Rasch nos advierte que no debemos confundir la «constitución» con el «derecho constitucional», pues la constitución, tanto como unidad de orden político y como acto directo de institucionalidad del pueblo, no puede ser reducida a un simple estatuto o compilación, tampoco se puede comprender la constitución como un orden jurídico que se convalida a sí mismo desde adentro, desde sus propias apropiaciones y propiedades normativas (Sanín Restrepo, 2009)․

En consecuencia, los usos que se le dan a ese discurso constitucional — como lenguaje vivo y en constante movimiento - en distintos sectores de la sociedad, están

\footnotetext{
${ }^{1}$ Nota de los autores: Paréntesis son nuestros y son ajenos al texto.
} 
en constante tensión y disputa. En términos de Foucault (2003), están en una lucha instintiva por el conocimiento del derecho y más específicamente de la constitución. En tal sentido, este choque por la significancia de la constitución (en un sentido político y no-estático) no es posible en condiciones de libre diálogo, ya que existe un discurso constitucional dominante que pretende imponerse al resto. En términos específicos, la explicación anterior se puede ejemplificar en una democracia constitucional latinoamericana a través de la espacialización de las relaciones de las prácticas de significación y sentido que le dan a la Constitución por un lado la capital — dominante y central - y por otro las regiones — externalidad pasiva—. La reacción de los relatos externos - de la periferia - ante el discurso hegemónico, genera una importante alteración en la comprensión y asimilación de lo jurídico-político y su intervención fundante en los procesos de subjetivación y la normalización de las estructuras de poder.

A partir de lo expuesto, el propósito del presente texto es trazar unas líneas preliminares que permitan sugerir unos ejes de análisis y comprensión que pongan en evidencia esa tensión entre los relatos externos y circundantes sobre la Constitución y el discurso regulador, central y dominante, a través del ensamble de ciertas adaptaciones situadas de las ciencias sociales sobre el poder, el sujeto, el espacio y el saber, con las cuales se dibujará la espacialidad de significación constituida. Lo anterior, se representará en imágenes sociosemióticas que explicarán las tensiones entre las prácticas discursivas de la capital y la región, simbolizadas como centro y periferia. Asimismo, las herramientas que se sugieren para trazar el campo de reflexión sirven como tipos de análisis que permiten una mayor comprensión y claridad del ámbito fenoménico en cuestión. El abordaje desde esta perspectiva sociocultural abre la posibilidad de integrar disciplinas de forma situada en el ejercicio investigativo y reflexivo, como base para sostener criterios críticos y transformadores.

El segmento 1 plantea un estudio general del análisis del discurso y del concepto de práctica de significación y sentido, para luego explicar el funcionamiento de la Constitución como discurso. El segmento 2 se ocupa de hacer una introducción al primer modelo sociosemiótico-metafórico a utilizar, siendo este la explicación del funcionamiento de prácticas de significación del discurso constitucional, según la espacialización a la manera de ondas que se reflejan en el agua a partir de un punto de impacto. El segmento 3 intenta articularse con el apartado anterior, en la medida que explica la adaptación del concepto de semiosfera al dibujo de la metáfora de las ondas, con el fin de comprender, en mayor medida, la tensión en el juego por el conocimiento del discurso constitucional; el escenario de disputa o de lucha entre el centro y la periferia estatal, que proviene de unas condiciones semejantes a nivel geopolítico. Y el segmento 4 abor- 
da el reto de establecer conexiones, vínculos y, en consecuencia, acoplar el ensamble entre posturas conceptuales como las de Teun Van Dijk, Enrique Dussel, Iuri Lotman, Antonio Negri, Ricardo Sanín Restrepo y otros, para ensayar así un nuevo giro comprensivo en las formas de análisis utilizados para el estudio de la Constitución y sus campos prácticos y discursivos.

\section{ANÁLISIS CRÍTICO DEL DISCURSO Y LAS PRÁCTICAS DE SIGNIFICACIÓN Y SENTIDO}

El primer acercamiento girará en torno a la teoría del análisis crítico del discurso (en adelante $\mathrm{ACD}$ ), que brinda elementos suficientes para comprender lo que está más allá de la vista, pues permite dar a conocer lo que se produce dentro de la realidad social humana, donde el lenguaje es una práctica social que guarda una estrecha relación con las relaciones de dominación y las formas en las que se pueden identificar.

Teun Van Dijk sustenta que el ACD se desarrolla en dos facetas del discurso: la primera como estructura lingüística y la segunda como fenómeno social. Como estructura lingüística el discurso incluye una explicación acerca de las estrategias y funciones gramaticales, estilísticas, retóricas y similares; como fenómeno social, el discurso se explica a través de una triada conceptual que revela su naturaleza práctica: discurso-cognición-sociedad; donde el término discurso se utiliza en sentido amplio como «acontecimiento comunicativo» que incluye la interacción conversacional, los textos escritos y también los gestos asociados, el diseño [...] y cualquier otra dimensión o significación multimedia; cognición que implica tanto la cognición personal como la cognición social, las creencias y los objetivos, así como las valoraciones y las emociones, junto con cualquier otra estructura, representación o proceso mental que haya intervenido en el discurso y en la interacción; y por último, el concepto de sociedad que incluye tanto las microestructuras locales de las interacciones cara a cara detectadas como las estructuras globales, sociales y políticas que se definen de forma diversa en términos de grupos, de relaciones de grupo (como las de dominación y desigualdad), de movimientos, de instituciones, de organizaciones, de procesos sociales o de sistemas políticos, junto con otras propiedades más abstractas de las sociedades y de las culturas (Van Dijk, 2003).

Los discursos constitucionales, como convenciones sociales, giran en torno a la segunda faceta expuesta por el autor, donde se hallan los elementos que tienen incidencia en las prácticas sociales que generan conflictos y tensiones entre la capital y la región. Para ello es necesario definir las estructuras discursivas que se analizarán con el fin de 
evitar que el trabajo se desborde en otros puntos que alejen la reflexión sobre el objeto ${ }^{2}$ de estudio.

La primera estructura a desarrollar es el contenido, ya que las proposiciones y el léxico utilizado por los sujetos encargados de la producción y reproducción del discurso jurídico, responden a la(s) ideología(s) de estos sujetos; ideología entendida desde la perspectiva de Thompson como i) las maneras en que se transmite y construye el significado mediante formas simbólicas de distintos tipos, ii) el contexto social donde se despliega y, sobre todo, iii) las relaciones de dominación que crean, que responden a la vez a diferentes estímulos de quien los emite (Wodak \& Mayer, 2003). Con lo anterior, se pretende un primer acercamiento al asunto del discurso y a la intención del mismo, ya que «los textos discursivos son muestras de combate donde están las huellas de los discursos e ideologías y donde el poder se convierte en condición capital de la vida social» (Wodak \& Mayer, 2003).

Los temas del discurso desempeñan un papel fundamental en la comunicación y en la interacción. Definidos como «macro estructuras semánticas» derivadas de las (micro) estructuras de significado, los temas representan el asunto «de que trata» el discurso, ya que, en términos generales, incluyen la información más importante de un discurso, y explican la coherencia general de los textos y las conversaciones (Van Dijk, 2003).

Así, una vez comprendidos los temas globales, es necesario pasar a los significados locales que requieren una aproximación al significado de las palabras, la estructura, coherencia y relaciones entre las proposiciones. Este ejercicio se da en razón a que los sujetos encargados del proceso discursivo hacen la elección de estos significados de acuerdo con el contexto donde operan ciertos esquemas mentales, según el acontecimiento y las creencias compartidas socialmente; Van Dijk expone que:

Al mismo tiempo, los significados locales son el tipo de información que (sometida al control general de los temas globales) más directamente influye en los modelos mentales, y por tanto en las opiniones y en las actitudes de los destinatarios. Junto con los temas, los destinatarios recuerdan mejor estos significados y los reproducen con toda facilidad, de ahí que puedan tener las más obvias consecuencias sociales (Van Dijk, 2003).

${ }^{2}$ En este contexto, más que utilizar el término objeto en un sentido racionalista instrumental o positivista lógico, lo que se pretende es reivindicar la distorsión de un fenómeno de estudio, entendiendo que dicho propósito o tema se servirá de reflexiones interdisciplinarias y transdisciplinares. 
Es por esto que más que un enfoque o una metodología de estudio, el análisis crítico del discurso (ACD) es una posición reflexiva, en palabras de Van Dijk «es más bien una perspectiva, crítica, sobre la realización del saber. Se centra en los problemas sociales, y en especial en el papel del discurso en la producción y en la reproducción del abuso de poder o de la dominación» (Van Dijk, 2003). Asimismo, intenta introducir la idea de resistencia que es una ruptura de las convenciones y de las prácticas discursivas estables como un acto de creatividad frente a la dominación.

Teniendo en cuenta las intuiciones, el discurso se estructura por dominancia, todo discurso es un objeto históricamente producido e interpretado, esto es, que se halla situado en el tiempo y en el espacio, y que esas estructuras de dominancia están legitimadas por las ideologías de grupos poderosos, la perspectiva de la lingüística crítica y el análisis del discurso permite analizar las presiones provenientes de arriba y las posibilidades de resistencia a las desiguales relaciones de poder que aparecen en forma de convenciones sociales (Wodak \& Mayer, 2003: 19).

Debido a su carácter crítico e interdisciplinario, el ACD es un modelo que sirve para el cuestionamiento de los paradigmas predominantes y se sirve de diferentes herramientas para construir un estudio sociológicamente informado de la realidad. Horkheimer, por ejemplo, creía que no se podía hacer un estudio desde un solo método de análisis, ya que esto es aceptar una noción distorsionada de la realidad; pero si se utilizan varios métodos estos se imbrican (Wodak \& Mayer, 2003); tal y como más adelante pueden relacionarse diversos modelos de análisis en el presente texto (metáfora de las ondas en el agua, semiosfera). En el mismo sentido, Van Dijk explica que «sin un método explícito y sistemático, no es posible generar ninguna observación socialmente útil o cognitivamente fiable, y tampoco pueden realizarse descripciones válidas» (Van Dijk, 2003).

Ahora que se ha comprendido el funcionamiento del ACD, es necesario destacar el objeto sobre el cual se aplica. En este caso, el objeto es el discurso constitucional, en el que se consigna la estructura política, social, cultural, económica y jurídica del Estado contemporáneo. Lo anterior evidencia la importancia de este discurso, ya que en el mismo se hallan plasmadas relaciones de dominación que intentan legitimarse en la producción y reproducción de imágenes afirmativas de los pilares del pensamiento occidental (la democracia, el mercado, los derechos humanos, las instituciones políticas, el individuo) en perjuicio de subjetividades marginadas e invisibles, opacadas o distorsionadas, que generalmente se encuentran ubicadas en la periferia social y espacial.

Las convenciones y representaciones que se originan del discurso tienen como función práctica hacer creer a los receptores que las interpretaciones que reciben son las 
correctas, afirmativas y posibles; y, por ende, que las que están fuera del discurso no son creíbles, son inválidas o meramente inexistentes (De Sousa Santos, 2010). Esta actitud se justifica en el supuesto de que el actor o sujeto que produce el discurso es aceptado y reconocido como la única autoridad existente y facultada para hacerlo. De este modo se hace referencia al control y la regulación que tienen los sujetos estatales sobre el discurso constitucional, y que en consecuencia elimina la posibilidad de la intervención y, por supuesto, del disenso. Los sujetos sobre los que recae el peso material y simbólico del discurso hegemónico se ven por tanto limitados a acoger y absorber pasivamente todo lo que se produce e irradia desde la capital (centro), lugar generador del proceso discursivo unívoco.

¿A qué se hace referencia con función práctica del discurso? A la concepción que Van Dijk hace del discurso como productor de acciones, que al ser discursivas son de sentido y significación (Van Dijk, El discurso como interacción en la sociedad, 1997). Hablar únicamente de «práctica» hace referencia a acciones, mientras que si se habla de prácticas de sentido y significación, tienen el propósito y el efecto de la reproducción y la propagación. Por tanto, es pertinente realizar una distinción entre sentido, significación y significancia, y de esta forma comprender las prácticas de significación y de sentido propias del discurso constitucional y su espacialización.

Fontanille denomina sentido a aquello que tiene una dirección, es decir, que tiene el propósito de designar un efecto de proyección como consecuencia de una práctica. Producto del sentido es la materia, que puede ser física, psicológica o cultural. «El sentido es, ante todo, una dirección: decir que un objeto o una situación tiene sentido, es en efecto decir que tiende hacia alguna cosa» (Fontanille, 2001: 21). Por otra parte, la significación es el producto organizado por el análisis y:

[...] está, pues, ligada a una unidad, cualquiera que sea el tamaño de esa unidad —la unidad optima, para nosotros, es el discurso-, y descansa sobre la relación entre un elemento de la expresión y un elemento del contenido; por eso se habla siempre de la «significación de [...] alguna cosa» (Fontanille, 2001: 22)

La significancia, en cambio, se refiere a la globalidad, al conjunto estructurado que permite el análisis de las unidades más grandes a las más pequeñas, como es el caso de las prácticas constitucionales: donde unas son dominantes y otras obedientes o sometidas. Estas modalidades se encuentran en la práctica del discurso constitucional, que comprende, por un lado, varios planos del lenguaje, un cuerpo percibiente y sientiente que abarca al mundo exterior (la periferia) y, a su vez, lo que pasa por la frontera; y por otro se encuentra el orden regulador (sintaxis) del contenido, que hace parte del mundo 
interior, es decir el centro generador (Fontanille, 2001). Los siguientes apartados usarán las herramientas conceptuales del ACD para establecer nuevos modelos de aproximación al fenómeno de los intercambios culturales en pugna por el sentido del discurso constitucional.

\section{TENSIÓN POR LA SIGNIFICACIÓN DEL DISCURSO: METÁFORA DE LA ONDAS}

Inicialmente, es pertinente hacer una descripción de cómo funciona la metáfora de las ondas, lo cual llevará a dar las razones o justificaciones de su uso simbólico en el presente texto. Las metáforas son, por lo general, imágenes adaptadas que sirven para describir un objeto a través de una imagen o representación. El lenguaje abre las posibilidades a través de las metáforas para comprender un fenómeno de diversas maneras: como es el caso de los intercambios desiguales en la construcción del discurso jurídico constitucional entre la centralidad dominante y las periferias marginadas.

Una piedra que cae en un cuerpo de agua estable genera una alteración de la quietud de la superficie, lo cual se evidencia en las ondas que emanan del punto de impacto y se van ampliando progresivamente. A nivel general, estas ondas se definen como ondas de propagación, pero a nivel específico pueden denominarse concéntricas circulares, ya que tienen la característica de provenir de un punto céntrico, pero se despliegan inevitablemente alrededor. En el mismo sentido, las ondas generan una vibración del agua a medida que la onda va avanzando, y si por ejemplo un flotador de pesca se encuentra en la superficie este se verá subiendo y bajando levemente de la estabilidad en la que se encontraba antes del impacto de la piedra; esta es, en efecto, otra característica de este tipo de ondas.

Ahora bien, este ejercicio de representación ubica el ámbito de estudio de la presente matriz conceptual en primer lugar en la metáfora de un centro y una periferia: entendido el centro como el punto de impacto de un objeto pesado o denso, y la periferia como el entorno que se abre, expande y espacializa paulatinamente. Si se tiene en cuenta que se dan tensiones e intensidades entre estos dos lugares, también puede notarse que esa relación es desequilibrada en la medida en que el centro posee códigos de significación dominantes que al actuar sobre determinados objetos establece unas prácticas de significación y sentido hegemónicas.

En segundo lugar, es posible decir que el modelo reflexivo y comprensivo de las ondas evidencia con mayor claridad la manera en que el centro parte como originador y regulador de la significación: es posible asimilar las ondas que emanan del punto 
céntrico — quieto e inmune a las ondas que produce — a las prácticas de significación y sentido dominantes que pretenden ocupar todo el cuerpo de agua, incluida la periferia, que puede tener otras prácticas diferentes e inusuales. Esto conduce ineludiblemente a un tercer aspecto: el hecho de que las ondas únicamente están viajando hacia el exterior, conservando el centro inalterable, pues la fuerza expansiva no logra alterar el núcleo originario. ¿Es posible que existan ondas en sentido inverso a las originadas por el impacto que permitan la tensión y el choque de unas prácticas de significación hegemónicas y otras periféricas? ¿Cómo se producen estas ondas reversibles e insubordinadas?

Las dos preguntas se pueden responder de manera preliminar con la continuación de la metáfora. Para esto hay que tener en cuenta que el cuerpo de agua de dimensión indeterminada no permite observar el control del discurso, pues solo observa la propagación infinita y sin respuesta de las ondas. $\mathrm{Si}$, por el contrario, las ondas en el agua se propagan en un estanque con forma irregular, hay un momento en que éstas se chocan con un muro-lindero que está delimitando el espacio. Inevitablemente, las ondas que inicialmente se alejaban del punto de impacto, ahora vuelven en diversas y más desordenadas direcciones al centro, camino en el cual también pueden chocarse constantemente entre sí. Tal evidencia responde al primer cuestionamiento, en la medida que existen ondas que contrarían la dirección de las que emanan del punto de impacto, pretendiendo justamente llegar a éste.

Respecto al segundo, se puede decir que esta reacción de las ondas también es observable en la tensión que existe por la definición o significación de artefactos socioculturales entre el centro y la periferia, como el derecho. La metáfora ilustra entonces la existencia de una lucha por dar significación a una práctica discursiva sociocultural. Este choque plural es el que da sentido a las ondas que vuelven al centro, pues estas propenden por un diálogo intercultural e intersubjetivo entre las múltiples lecturas e interpretaciones que depende de un espacio, un ritmo y un tiempo. Las ondas que se regresan al centro son producto del desorden, de los límites que impone la periferia al centro, de la oposición que hacen las prácticas discursivas exteriores contra las prácticas dominantes, tal contradicción a las significaciones hegemónicas plantea un límite y a la vez una fisura al saber instituido y normalizado, todo lo cual propicia la interpelación discursiva y tensiva entre grupos céntricos y periféricos.

Justamente lo expuesto a través de la metáfora de las ondas en el agua, ilustra la tensión de discursos constitucionales y sus respectivas prácticas de significación, entre la capital hegemónica y las regiones que contienen singularidades dominadas, haciendo inoperante la visión unívoca y totalizante de la Constitución como elaboración netamente jurídica. El desarrollo del dibujo trazado desembocará en una comprensión más am- 
plia y diversa de lo que genera descubrir, evidenciar y seguir esos movimientos y alteraciones a la quietud en términos socioculturales discursivos.

\section{LOS DISCURSOS CONSTITUCIONALES Y LA SEMIOSFERA: CENTRO Y PERIFERIA}

Los significantes centro y periferia son recursos explicativos que expresan el reconocimiento de relaciones asimétricas de poder y saber que se manifiestan particularmente en la producción de sujetos y conocimientos que se autolegitiman para deslegitimar a otros que pasarán a ser negados o invisibilizados.

En torno a la posición de América Latina en un paisaje global de gestación del conocimiento, Enrique Dussel plantea que el continente no sufrió la herencia de una sola modernidad, sino de dos: la primera que va desde la invención de América como paraje periférico en 1492 y la segunda que empieza con el pensamiento ilustrado y se confirma con el apogeo de la revolución industrial. Dussel explica que la modernidad no se dio solo desde el punto de vista eurocéntrico ilustrado del siglo xvII, y que por lo tanto la conquista e invención de América, la lucha de media Europa contra el avance del Imperio Otomano y la recepción de textos griegos desde las bibliotecas del Imperio Bizantino o Romano de Oriente (lecturas base del pensamiento supuestamente europeo de Aristóteles, Platón y los diálogos socráticos), no fueron acontecimientos aislados. Por el contrario, son estos los que dan origen a la primera modernidad, aquella proveniente de los sectores que, posteriormente, se convierten en la periferia de Europa.

Dussel utiliza el centro y la periferia para explicar la forma en que Europa se fundó como centro del mundo auto-referencial de la modernidad, generando la invención lógica y consecuente de territorios ajenos, marginales, no-ilustrados y periféricos (Dussel, 2000). Tanto América como Oriente se transformaron en espacios de interés colonial, más no de intercambio transcultural. De ahí parte la intención de Europa de hacerles llegar (a través de la represión violenta primero y de la construcción simbólica de instrumentos de poder y dominación después) el conocimiento científico, racional y civilizado. El modelo sistema-mundo, tomado de Wallerstein, sirve también para ilustrar la manera en que los imaginarios ilustrados se convierten en referencias incontrovertibles para las culturas periféricas. El eurocentrismo moderno dibuja las reglas de juego discursivas a partir de las cuales se produce conocimiento, se ejerce el poder y se piensan las instituciones sociales (Pachón, 2007).

No obstante, la lectura de Dussel es más global e histórica que estatal. Se plantea el objetivo de reivindicar la producción de conocimiento latinoamericano que se des- 
ligue de las categorías, parámetros discursivos y relaciones de poder eurocéntricas. Consecuencia de lo que describe Dussel, el sistema-mundo también se ha desplazado al territorio de los Estados-nación de Suramérica. Las constituciones de estos países fueron construidas a partir de las referencias teóricas y modelos europeos o norteamericanos. Así, la constitución política es la centralidad en un estado donde las regiones son periferia y se las margina de la conjunción de un discurso constitucional dinámico. El modelo centro-periferia explicado por Dussel basta para explicar los antecedentes históricos, la construcción de la modernidad autopoietica, más no para abordar las relaciones que se establecen en los discursos constitucionales de cada país.

La semiosfera de Lotman, permite realizar una lectura amplia y detallada del centro y la periferia como fenómeno social y las consecuencias que su relación trae a la cultura y la reflexión del texto constitucional como artefacto discursivo. La semiosfera se entenderá como un mapa abstracto que tiene dos características principales: su carácter delimitado y su irregularidad semiótica. El primero permite una homogeneidad e individualidad semiótica (1996) porque todo debe conformar un organismo único y, dentro de él, se encuentran múltiples singularidades que constituyen el sistema-semiosfera. El carácter delimitado permite la creación de fronteras entre culturas externas - no-textos- y las culturas dominantes - textos- Esa frontera está acompañada de un traductor, que permite el intercambio de información.

La frontera semiótica es la suma de los traductores-«filtros» bilingües pasando a través de los cuales un texto se traduce a otro lenguaje (o lenguajes) que se halla fuera de la semiosfera dada. El «carácter cerrado» de la semiosfera se manifiesta en que ésta no puede estar en contacto con los textos alosemióticos o con los no-textos. Para que éstos adquieran realidad para ella, le es indispensable traducirlos a uno de los lenguajes de su espacio interno o semiotizar los hechos no-semióticos (Lotman, 1996: 4).

Esa frontera pretende quitar los abismos creados entre culturas, pero tiene el propósito de limitar la penetración de lo externo en lo interno, es decir, quiere fortalecer cada vez más el statu quo de la semiosfera cerrada, y lo que entra del exterior traducirlo, pero filtrando la información de entrada y salida, para adaptarla.

En el nivel de la semiosfera, significa la separación de lo propio respecto de lo ajeno, el filtrado de los mensajes externos y la traducción de éstos al lenguaje propio, así como la conversión de los no-mensajes externos en mensajes, es decir, la semiotización de lo que entra de afuera y su conversión en información (Lotman, 1996: 9). 
Esa configuración de la frontera permite el intercambio entre centro y periferia, tanto en un contexto global, como el caso de la tensión oriente-occidente, norte-Latinoamérica u occidente-Latinoamérica (como mencionaba Dussel); y el caso más particular es la tensión figurada entre las capitales y las regiones en los estados-nación latinoamericanos.

Otra de las características de la semiosfera es su irregularidad semiótica, que tiene como fin ordenar la semiosfera. Esta irregularidad de no-textos y multiplicidad de los mismos hace que se presuma y conforme una integridad. El espacio semiótico tiene la presencia de estructuras nucleares dominantes, las cuales están rodeadas de un mundo semiótico amorfo (periferia) que está subordinado por códigos céntricos de significación. Ahora bien, si se da la dominación por parte de una de las estructuras nucleares, se tienen la pretensión de describirse a sí misma y también el espacio periférico (Lotman, 1996). Entonces con la irregularidad del mapa semiótico se construye el nivel de la unidad ideal del mismo. Lo que produce el fortalecimiento de las fronteras entre centro y periferia, pero con el propósito de unificar y describir todo de una única forma.

Para ilustrar esta traducción de códigos dominantes Lotman expone como ejemplo la territorialidad de los nómadas bárbaros. Cuando estos se asentaban en la periferia de una gran ciudad, había la necesidad de una frontera con el fin de garantizar el contacto con entre los dos lugares, de unir dos esferas de la semiosis; donde tomar conciencia de que hay otra esfera, es decir, el reconocimiento de que existe la periferia, hace que la función de la frontera sea crear esa conciencia de su propia especificidad, acentuando su determinación y su carácter absoluto. «La frontera tiene también otra función en la semiosfera: es un dominio de procesos semióticos acelerados que siempre transcurren más activamente en la periferia de la oikumena cultural, para de ahí dirigirse a las estructuras nucleares y desalojarlas» (Lotman, 1996: 8).

Entonces, se dice que la pretensión de la periferia es desestabilizar los códigos de significación dominantes que se erigen como absolutos y únicos referentes de sentido dentro de la semiosfera. La ilustración del ejercicio pone en evidencia una constante tensión entre el centro y la periferia, en la cual siempre existirá la resistencia de lo externo hacia la dominación que ejerce lo interno como integridad de significaciones. El objeto que esté discutiéndose puede ser cualquiera, pero lo importante es evidenciar la constante disputa por darle sentido y significación, a través de distintas descripciones lingüísticas. De acuerdo al interés de la indagación, a continuación, se analizará la relación de esta introducción ejemplificante desde la semiótica con la configuración de un discurso constitucional en el centro y en sus alrededores, y cómo esta relación es desequilibrada e invisibilizada. Se procede a explicar cómo funciona una posible dinámica de la semiosfera: la tensión entre pueblo y multitud. 


\section{MULTITUD Y PUEBLO EN LA SEMIOSFERA}

El discurso constitucional será el objeto de estudio a profundizar y distorsionar. Éste puede crearse y reproducirse tanto en el ámbito interno de la semiosfera, como en la externalidad de la misma. Esto quiere decir que existe una configuración de sentido dominante sobre el texto constitucional y existen no-textos constitucionales — para hacer referencia a Lotman- que se encuentran, por supuesto, deambulando por la periferia. La significación de la constitución que proviene de lo externo se mantiene aislada, debido a que la búsqueda del campo interno es mantenerse hermético a los textos que le son extraños. Por una parte, en el centro, están los discursos hegemónicos y cerrados del discurso constitucional, mientras que, en la periferia, se encuentran la sedición a los mismos. La justificación de esta sedición es justamente lo que explica Lotman en su ilustración de la semiosfera: que la periferia tiene la intención de desestabilizar los códigos de significación dominantes; como también sucede con las ondas que quieren regresar al centro, pero de forma desordenada y con diferente significación a como fueron recibidas. Entendido lo anterior, es pertinente tratar de ubicar en el ámbito de lo político, el caso planteado desde la semiótica.

Para ello es apropiado indagar por la transición entre modernidad y transmodernidad. La modernidad es el momento donde la ilustración es protagonista, y por tanto la riqueza de la razón individualista pasa por encima de todas las ciencias y pensamientos adyacentes o divergentes. También es el momento en que la configuración del Estado busca ser una sola, donde la sociedad se ordena en torno a este de manera homogénea a través de sus instituciones, regidas por principios básicos de igualdad formal, de libertad restringida y de autonomía de la voluntad. La sociedad moderna es el mejor ejemplo del concepto de 'pueblo', a partir de los cuales se crean los Estados-nación. En el pueblo deben erradicarse todo tipo de conflictos y afianzar la convivencia pacífica de todos los ciudadanos, teniendo como fin el respeto de la individualidad, a pesar de que esta no se exprese, sino simplemente se quede expectante, ejerciendo obediencia al Estado. Este es uno de los principales baches de la modernidad: el intento de erradicar el conflicto y la disputa de ideas.

Otra arista crítica de la modernidad puede aportarse desde la visión ideológica de la ética-cívica democrática de la cual proviene la exaltación del deber laico en función de la individualidad apaciguada. A pesar de que la ilustración, la secularización del saber y de las relaciones sociales y el individualismo trajeron consigo la formalización de derechos básicos en las incipientes democracias liberales, ahuyentaron una lectura transcultural, multitudinaria de la construcción del discurso constitucional. El deber, en este sentido, es más una trampa discursiva que una condición moral categórica (Lipovetsky, 
1992); no es una obligación con la alteridad, sino con la nación, con la patria, con la quietud misma, con la estabilidad del control ejercido por el Estado. Dicha actitud se convierte en el imaginario que sirve a las personas para comprometerse en un sentido estrictamente jurídico-formal con el otro: las subjetividades periféricas, el movimiento, las cosmovisiones anti-cívicas serán, cuando menos toleradas, más no integradas ni escuchadas. La trascendencia de esta perspectiva sobre lo moral se ve reflejada en las promesas inconclusas de los derechos humanos (Ariza, 2010) y la indisposición para la inclusión efectiva de sistemas jurídicos plurales (Ordóñez, 2009), por mencionar algunos ejemplos. Este punto de vista crítico es esencial para entender la ética democrática ilustrada desde otra orilla epistemológica: una que asume la modernidad como un ocultamiento de subjetividades subalternizadas.

En términos transmodernos, el discurso de lo político cambia, justamente en razón a la crítica de la quietud y la homogeneidad de la ilustración: la guerra, la violencia, y el conflicto ya no se entienden como erradicables, sino que, al contrario, son entendidos como características de las relaciones humanas. Según Foucault, todas las relaciones humanas deben ser entendidas a su vez como relaciones de poder, ya que, a partir de instintos - de dominación- que se encuentran en tensión, se produce — para poner un ejemplo del mismo Foucault - el conocimiento (Foucault, 2003). Esto evidencia que la contemporaneidad, y a su vez, la transmodernidad (desde miradas críticas), es el tiempo de la lucha y del caos, en contraposición al orden y el hermetismo de la modernidad. Volviendo nuevamente al tema de la guerra, De Lucchese, citado por Antonio Negri, refiere lo siguiente:

En la época contemporánea, Foucault expresó más que cualquier otro el carácter conflictivo de la historia y su sentido anfibio: por un lado, en tanto expresión de los conflictos, de las luchas, de las revueltas [...] por el otro, como instrumento de lucha teórica a través del orden político. (Negri A. , 2011: 18)

Justamente, a partir de esta noción de conflicto y de tensión en las relaciones humanas, se describe la imposibilidad de reducir la sociedad al concepto de «pueblo», y se propone la construcción de su idea antagónica, la de una «multitud» integrada por singularidades.

En este punto la dicotomía pueblo-multitud lleva a recordar la acaecida entre Hobbes y Spinoza. Hobbes creía que el Leviatán -El Estado- podría proteger al pueblo de su propio estado de naturaleza, volviéndolo dócil, y reconociendo el papel del contrato social como trayecto a la obediencia. El paradigma contractualista redujo las subjetividades a la homogeneidad, a la unidad que anulaba las singularidades. Priorizaba la cons- 
trucción del Estado como ente ficcional-organizador, frente a la comprensión de la naturaleza de los individuos que lo conformaban. Al Hobbes asumir la existencia de una situación caótica e incontrolable entre los hombres, se saltó la reflexión —más profunda- por la subjetividad.

Spinoza se sitúa en las antípodas de la línea de pensamiento moderno y clásico, que es más afín a Kant y Hegel, que a Maquiavelo. Para Spinoza era muy relevante el estudio de la naturaleza humana, de la subjetividad como parte de la reivindicación de un individualismo que aspirara a la heterogeneidad. El sujeto spinoziano se erige, entonces, como aquel que puede percibir un objeto de forma distinta, según sus rasgos racionales diferenciales. Esto expresa un interés por la conservación de toda subjetividad en pleno desarrollo de su diferencia.

No obstante, esa mirada materialista podría dar la razón a Hobbes, en el sentido de que la duda por las relaciones intersubjetivas quedaría al arbitrio de la fuerza y de la dominación entre los sujetos. Ante tal circunstancia, Spinoza propone un modelo que, aunque se basa en la razón, propugna por unos criterios distintos al propuesto por el racionalismo ilustrado; apunta a la disparidad y a la lucha entre las subjetividades en función de un proyecto inacabado de creatividad en la conformación del tejido social.

La potentia se erige como contraposición a la potestas; donde la primera es la inmanencia de la individualidad entendida en función de lo colectivo, mientras la segunda es la pretensión de homogeneidad y búsqueda de una institución política estática.

No hay una renuncia al poder en favor de una instancia de dominación, sino la apuesta por la producción colectiva de un poder itinerante, nómada, siempre en cuestión y, por ello mismo, revolucionario' Es la libertad de la subjetividad que se hace producción de liberación colectiva (Aragues, 1996).

El significado de potencia se asimila al constante movimiento. Contrario a la posición contractualista-moderna, un pacto social no zanja la naturaleza salvaje del ser humano y convierte a una sociedad en un terreno de armonía; la postura ilustrada-ordenada puede erradicar el devenir político palpable y latente que se encuentra arraigado en cada persona y que se intensifica en torno a un proyecto colectivo al que se denomina multitud. De esta forma Spinoza da apertura a las reflexiones posmodernas que indagan por la praxis de la propuesta inicial. La disyuntiva entre el pueblo y la multitud se hace evidente.

Entre las lecturas contemporáneas de los conceptos antes referidos, una re-definición de potencia puede ser: la expresión de la imaginación como estructuradora de la 
racionalidad (Negri A., 2011). Aquí Antonio Negri hace una interpretación de Spinoza que insiste en la disparidad, en el movimiento, en la tensión entre singularidades dentro de la sociedad. La potencia necesita del movimiento y, por tanto, necesita heterogeneidad, algo impensable en el mundo como 'pueblo'. Es así que, según lo anterior, se configura el concepto de multitud.

La multitud es [...] una multiplicidad irreducible, una cantidad infinita de puntos, un conjunto diferenciado, absolutamente diferenciado. ¿Realmente piensa que el conjunto de ciudadanos puede reducirse a la unidad? Es absurdo. La multitud de las singularidades no puede reducirse a la idea de pueblo. El pueblo ha representado durante el periodo moderno una reducción hipostática de la multitud (Negri, 2003: 107).

La multitud es el desorden y lo abigarrado, es la antítesis del pueblo. Funciona siempre bajo el movimiento constante de las singularidades que la integran y debe permitirle a dichas singularidades, (des)organizadas a partir del movimiento, la capacidad de expresarse o, en otras palabras, de resistir. Aquí aparece otro concepto importante para Negri: la seditio — sedición- como resistencia al poder, a la dominación. Esta resistencia permite recordar y articular el concepto de Van Dijk sobre el ACD; entendiendo que la disparidad de discursos, la lucha por la significación muestra que la universalidad del sentido y del discurso es imposible.

Es adecuado ahora volver al ejemplo de la semiosfera de Lotman, donde es posible ilustrar la ubicación del pueblo y la multitud. Acomodadas a las características expresadas al inicio del texto acerca de lo interno y lo externo, la multitud encaja en el ámbito periférico, mientras el pueblo puede ubicarse perfectamente en el centro. El pueblo posee unos instrumentos de codificación dominantes, que dotan de sentido al lenguaje del discurso constitucional del centro. Por el contrario, el papel de la multitud es, a partir de su capacidad de expresión y el derecho de resistir, desestabilizar el discurso constitucional hegemónico. Expone Negri,

Pero ya no hay un fuera respecto del sistema capitalista y por eso también el gueto y las periferias están dentro de él. Desde una perspectiva política, esta observación me parece extraordinariamente importante, pues una periferia que se revela ataca inmediatamente el centro del poder [...] Una periferia que se revela produce una crisis en todos los órdenes sociales y no sólo en los de la periferia. Esta interioridad de la periferia, tanto en el ámbito urbano como en la dimensión mundial, es una interioridad inderogable para el capital, atraviesa todos los países de modo determinante e impone una recalificación de todas las relaciones de poder (Negri, 2007: 147). 
El problema de esta ejemplificación se sitúa en el establecimiento de la frontera. Para graficarlo, en la frontera se puede entender que existe lo que llamaremos peajes de traducción lingüística, que sirven para poner a dialogar a los textos con los no-textos. En el caso del discurso constitucional dominante y el periférico, el dominio que ejerce el centro sobre el discurso alterno de la periferia es tan fuerte que busca desligarlo de sus intereses. Al pueblo, homogéneo y unívoco no le interesa establecer diálogos con la multitud, sino que, al contrario, busca marginarla de los espacios de gestación del saber. Así las cosas, para las prácticas de significación y sentido externas, pasar la frontera en dirección al centro es difícil debido al costo de los peajes de traducción que impone el centro.

Menciona Sanín Restrepo (2009) que el centro, entendido como un universal con un contenido ideológico negado desde la razón cínica $^{3}$, «determina ya todo el lenguaje y es el límite mismo de la realidad que experimentamos, sin posibilidad alguna de salirse de sus bordes encerrados en sí mismos». De la misma forma, Pierre Bourdieu ha ilustrado hábilmente la desconexión con la creatividad a partir de su idea de campo jurídico hermético (Bourdieu, 2000), donde un lenguaje propio, científico y unívoco se presenta como límite al intercambio cultural y de pensamiento, entre la hegemonía del centro y las periferias en movimiento.

El discurso constitucional, por supuesto, no se escapa de esta reflexión; mucho más al entender que las teorías del derecho dogmáticas y hegemónicas manifiestan una clara distinción entre derecho y política, estableciendo que una vez creada una constitución, el texto constituido deberá atarse al lenguaje jurídico del sistema y procurará su determinación y cumplimiento. Una vez se establece un discurso constitucional central (con un trasfondo ideológico, como ya dijimos), las demás manifestaciones, distorsiones, interpretaciones y variantes del discurso o incluso creaciones constitucionales producto de cosmovisiones y manifestaciones culturales periféricas, harán parte de un escenario de discusión no central, no científico y no constituyente.

Esto indica una imposibilidad de reconocer el carácter potente de los movimientos sociales, campesinos o indígenas; al entenderse estas comunidades como sujetos productores de conocimientos no-instuticionalizados, (no-textos constitucionales) el discurso central y dominante asume una postura que impide la recepción e intercambio de las formas en que se producen los diferentes discursos constitucionales en constante pugna. Alega el poder central-estático que la única manera de dialogar es que las ideas

\footnotetext{
${ }^{3}$ Véase Sloterdijk, Peter (2003). Crítica de la Razón Cínica. Madrid, Editorial Siruela.
} 
y propuestas de la periferia multitudinaria se hagan bajo las normas discursivas de la constitución hegemónica: se impone así, el peaje-límite de traducción lingüística ya referido.

Por otra parte, y particularmente extraídos de la obra de Negri, los conceptos de poder constituido (potestas) y poder constituyente (potentia) tienen incidencia en la configuración del discurso constitucional. A propósito se ha dicho que:

La teoría de Negri gira en torno a la distinción entre poder constituyente y poder constituido. Poder constituyente es el poder directo de las personas por encima de cualquier representación: en términos de Negri, es el poder de la multitud (Field, 2012).

Es posible deducir entonces que el poder constituido, por su parte, es el poder que se encuentra en el centro de la semiosfera, es decir, el que determina el pueblo ordenado, organizado, que tiene la capacidad y libertad formal de elegir y ser elegido. Del otro lado, como ya lo menciona Field, el poder constituyente refiere la expresión de la multitud, en efecto, desde la perspectiva de la periferia.

El mejor ejemplo para comprobar este vínculo entre la semiosfera y la dicotomía pueblo-multitud (poder constituido-poder constituyente, respectivamente), es la visión totalizante del Estado constitucional moderno occidental. Respecto a esto, Negri manifiesta que es sorprendente cómo se prefirió la quietud sobre el movimiento, la pasividad sobre lucha, y cómo esto trajo consecuencias nefastas para las sociedades modernas e, incluso, postmodernas: «Así es como falla el intento de representar la fuerza dinámica de lo político entendido democráticamente, la seditio, a través de su limitación contractual y/o constitucional» (Negri A. , 2011: 19). Al retomar el concepto de seditio, como capacidad de expresión de la multitud, pretende la búsqueda de la emancipación, fin de todo movimiento contra hegemónico.

Lo que realiza el Estado constitucional moderno es totalizar las perspectivas del discurso constitucional, generando un pueblo homogéneo que haga parte de la legitimación de tal Estado y se encarga de ejercer dominio sobre los alter-discursos o las perspectivas disidentes. El papel del pueblo es, para ponerlo en términos Negrianos y globales, el del Imperium, y el de la multitud el de la democracia revolucionaria que busca la manifestación real de la libertad:

A partir del desarrollo de la indignación nace, por ejemplo, la sedición; pero a partir del desarrollo de la sedición se abre la expansión revolucionaria de la libertad: aquí está la base que permite oponer al imperium la potencia de desarrollo de una verdadera democracia revolucionaria de las luchas de la multitud (Negri, 2011: 19). 
Así las cosas, y para concluir este segmento, es relevante confirmar la tensión entre prácticas de significación del discurso constitucional entre un ámbito interno y otro externo del modelo. La semiosfera sirve como modelo de análisis para ilustrar esto. Siempre que existan las dicotomías centro-periferia, homogeneidad-heterogeneidad, pueblo-multitud, poder constituido-poder constituyente, es posible hablar de una distancia mediada por fronteras (peajes de traducción) en donde se chocan constantemente singularidades: unas que pretenden reproducir el discurso céntrico, y otras que buscan desestabilizar ese discurso con alter-prácticas de significación de ese discurso hegemónico. De tal suerte que la semiosfera es un espacio de constante movimiento, de potencia, de acontecimiento, nunca de quietud y jamás de discurso unívoco. Esto es, claramente, un canto de batalla contra maneras dogmáticas de entender el derecho, la sociedad, el Estado y, específicamente, la Constitución.

\section{CONCLUSIONES}

El recorrido teórico realizado anteriormente permite establecer un punto de partida conceptual, unas posibles perspectivas de análisis y unas distorsiones o reinvenciones epistemológicas que replantean el estudio que se pretende realizar de la Constitución como discurso. Esto genera una serie de conclusiones preliminares que se conectarán con futuras investigaciones e indagaciones de carácter más específico y práctico.

En primer lugar, es posible observar y resaltar el aporte del estudio sociosemiótico del discurso como método de comprensión de un objeto interdisciplinario como el discurso constitucional. Justamente, la intervención de diversas disciplinas manifiesta una dificultad epistemológica en la aproximación al objeto de estudio en cuestión, la cual se puede resolver, al menos en un rubro liminar, a través de diversos enfoques de análisis socioculturales. Se han esbozado las características y elementos principales de posibles dibujos que ilustran la manera en que funcionan las relaciones de poder entre singularidades que pretenden dar significación al discurso constitucional: tanto la metáfora de las ondas en el agua y la semiosfera sirven como esquemas de observación de las tensiones entre prácticas de significación y sentido internas y externas. Es pertinente agregar que la presencia de estos modelos de análisis en el texto tiene como fin crear un sustento teórico que permita un estudio crítico-reflexivo de los fenómenos sociales y las condiciones de poder generadas a través del discurso constitucional para su posterior utilización en la praxis. En tal sentido apunta el filósofo boliviano Farit Rojas Tudela, 
La ambición de una teoría (mucho más si ésta es una teoría general) es posibilitar la lectura, comprensión y praxis estándar — de un objeto de estudio — [...] La teoría de una representación abstracta de la posible praxis. La teoría en tanto herramientas de interpretación es una invitación a la práctica de la misma (Tudela, 2012: 96).

En esa dimensión práctica, estableciendo una relación de intercambio entre la theoria y la praxis, podemos evidenciar que tanto objeto como sujeto podrían confundirse en el entramado de los modelos epistemológicos propuestos. Intercambiar los roles y lugares en el mapa semiótico de la semiosfera y en la metáfora de las ondas, permitirá afrontar la interpelación del derecho constitucional por parte de grupos históricamente vulnerados y opacados, que pasan a enunciar y decir lo jurídico, en lugar de ser sujetos cifrados, grises y homogéneos. Lo anterior nos lleva a pensar y estudiar un(os) movimiento(s) constituyente(s) o destituyente(s) (que deconstruyan el discurso constitucional central) reconocidos y reivindicados a través de la fundamentación teórica de epistemología(s) diverigente(s); donde se comparten conceptos, perspectivas y modelos que contrarían el carácter imperecedero de dinámicas de poder, y que refutan, rechazan o distorsionan los lenguajes herméticos e irrefutables promovidos desde el centro hacia la periferia.

El soberano no está parado como una divinidad solitaria supervisando sus dominios (centro), está tanto adentro como afuera del derecho, tanto dentro como fuera del sistema normativo que crea pero que a la vez lo determina. Es en ese sentido que se refuerza el hecho que los universales (discurso dominante) son imposibles en su auto-procedencia, pues cualquier sentido de lo universal (de lo quieto, inmutable y homogéneo) proviene de la brecha, de la paradoja de ser un enunciado parado en el umbral que separa el adentro y el afuera del normativo y lo constitutivo (peajes de traducción lingüística). Por tanto, el universal no puede formular los imperativos que dicten una diferencia tajante entre lo político y lo jurídico. La decisión sobre las diferencias no está ni adentro ni afuera de la diferencia, es la diferencia misma, es la brecha constitutiva de ese adentro y de ese afuera (de ese centro y de esa periferia) (Sanín Restrepo, 2009) ${ }^{4}$.

En concordancia con lo anterior, los ejes y enfoques de análisis imaginados y sugeridos en el presente texto son tan solo una aproximación al estudio del discurso constitucional en el centro y la periferia, y más específicamente en la relación capital-región a través de la mediación o agencia jurídicopolítica. Colombia es el país que hoy convoca

\footnotetext{
${ }^{4}$ Los paréntesis son nuestros y son ajenos al texto.
} 
esta reflexión, debido a la necesidad de establecer cómo funcionan, en la semiosfera colombiana, los discursos constitucionales periféricos y céntricos, para así comprender de manera más amplia, los fenómenos políticos, jurídicos, sociales y culturales que se presentan en el espacio simbólico y material de lo nacional. Esto debido a la sospecha de los investigadores por la desarticulación y el limitado y controlado intercambio sociocultural discursivo entre la capital y las diversas regiones. Estas aproximaciones se verán desarrolladas en mayor medida, al hacer una utilización de las herramientas teóricas en el terreno del campo social, para configurar un entendimiento completo de los múltiples y posibles discursos constitucionales del país, que se chocan e interrelacionan bajo condiciones limitadas y concertadas por la capital; en otras palabras, prácticas de significación dominadas sobre otras que se ubican en el mapa discursivo. Hacer evidentes estas relaciones, explorar sus razones, entender sus alcances y dimensiones serán las inquietudes a resolver desde el ámbito sentipensante de la investigación y la reflexión.

Ineludiblemente, los planteamientos anteriores conllevan a la apuesta por la inclusión de las subjetividades y grupos sociales marginados en las regiones. Reivindicar la voz de los campesinos, de los indígenas, de los estudiantes, de los sindicatos, de los trabajadores - por decir algunos - es también exaltar y darles relevancia a los discursos constitucionales (constituyentes) alternos que emiten, los cuales, por lo general, buscan desestabilizar el discurso hegemónico capitalino.

¿Cómo sería posible la transformación social y cultural por la vía constitucional, si el movimiento o poder constituyente periférico debe mantenerse atado y condicionado, incluso a la subalternidad y la exclusión (también por omisión), que manifieste el texto constitucional dominante o sus voceros institucionales?

La importancia de este ejercicio radica en que al generar dicha revisión e imaginación de las prácticas de significación y sentido que sobre la Constitución pueden ofrecer los grupos periféricos-regionales, se puede empezar a evidenciar y exigir una justicia enunciativa y espacial fundada en el hacer visible y audible a esta multitud viva negada.

\section{BIBLIOGRAFÍA}

Aragues, J. M. (1996). «Spinoza y el poder constituyente». En Philosophica 8, 79-94. Ariza, R. (2010). «Los derechos humanos en América Latina; una promesa sin cumplir». En Diálogo Político, Públicación trimestral de la Konrad Adenauer-Stiftung Año XXVII - No.4, 73-90.

Bourdieu, P. (2000). La fuerza del derecho. Elementos para una sociología del campo jurídico. Bogotá: Siglo del Hombre Editores. 
Broekman, J. (1997). Derecho, filosofía del derecho y teoría del derecho. Bogotá, Colombia: Temis.

De Sousa Santos, B. (2010). Refundación del Estado en América Latina. Perspectivas desde una epistemología del Sur. Bogotá: Siglo del Hombre Editores; Universidad de los Andes; Siglo XXI Editores.

Dussel, E. (2000). «Europa, modernidad y eurocentrismo». En E. Lander. (comp.), La colonialidad del saber: eurocentrismo y ciencias sociales. Perspectivas latinoamericanas (pág. 246). Buenos Aires, Argentina: CLACSO, Consejo Latinoamericano de CIencias Sociales.

Field, S. (2012). «Democracy and the multitude: Spinoza against Negri». En Theoria, 21-40.

Fontanille, J. (2001). Semiótica del discurso. Lima: Fondo de cultura económica.

Foucault, M. (2003). La verdad y las formas jurídicas. Madrid: Gedisa.

Lipovetsky, G. (1992). El crepúsculo del deber. España: Anagrama.

Lotman, I. (1996). La semiosfera I: La semiótica de la cultura y el texto. Madrid: Cátedra.

Negri, A. (2007). Goodbye Mr. Socialism. La crisis de la izquierda y los nuevos movimientos revolucionarios. Barcelona: Paidós.

Negri, A. (2011). Spinoza y nosotros. Buenos Aires: Nueva visión.

Negri, T. (2003). Del retorno: abecedario político. Buenos Aires: Random House Mondadori.

Ordóñez, J. E. (2009). «Sistema(s) Jurídico(s) Indígena(s)». En Revista Crítica Jurídica No. 27, 85-117.

Pachón, D. (22 de Marzo de 2007). Modernidad, eurocentrismo y colonialidad del saber. Bogotá: Instituto Pensar Universidad Javeriana.

Sanín Restrepo, R. (2009). Teoría Crítica Constitucional. Bogotá: Pontificia Universidad Javeriana, Facultad de Ciencias Jurídicas: Grupo Editorial Ibañez.

Tudela, F. R. (2012). «Hacia una nueva gramatica constitucional». En Revista de investigaciones jurídicas Unam, 96.

Van Dijk, T. (1997). El discurso como interacción en la sociedad. Barcelona: Gedisa.

Van Dijk, T. (2003). «La multidisciplinareidad y el análisis crítico del discurso: una alegato en favor de la diversidad». En R. Wodak, \& M. Mayer, Métodos de análisis crítico del discurso (págs. 143-177). Barcelona: Gedisa.

Wodak, R., \& Mayer, M. (2003). Métodos de análisis crítico del discurso. Barcelona: Serie Cladema. 